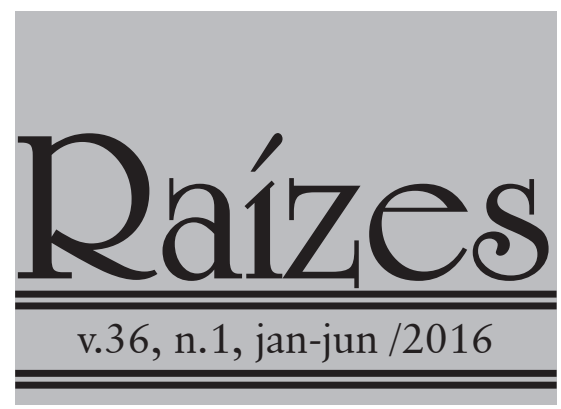

\title{
A CONSCIÊNCIA DAS CLASSES SUBALTERNAS EM ROGER BASTIDE E EM MARIA ISAURA PEREIRA DE QUEIROZ
}

\author{
Dora Vianna Vasconcellos \\ RESUMO
}

Maria Isaura e Roger Bastide apontam para o papel ativo desempenhado pelas camadas subalternas, reconhecendo que a agência individual é o meio a partir do qual ocorre o aumento do dinamismo social em sociedades como a nossa, em que as desigualdades sociais entre as camadas dificilmente se materializam em conflitos entre classes opostas. Ainda que apresentem esse ponto em comum, os autores parecem divergir quanto à orientação que a agência individual deve assumir para que haja transformação social. O presente artigo se propõe a elucidar esta suposta divergência, tomando como referência o diálogo que os dois autores travaram com a sociologia francesa, da qual descenderia a discussão sobre a atuação de indivíduos e grupos em processos de mudança social e o papel desempenhado pelas representações coletivas na conformação de seus comportamentos.

Palavras-chaves: Pensamento Social Brasileiro; Sociologia Política; Mudança Social; Consciência das classes subalternas

\section{THE SUBALTERN CLASSES CONSCIENCE IN ROGER BASTIDE AND MARIA ISAURA QUEIROZ PEREIRA}

\begin{abstract}
Maria Isaura Pereira de Queiroz and Roger Bastide call attention to the active role of subaltern classes, acknowledging that the individual agency is an instrument to increment social dynamics in societies like ours, where social inequalities between classes hardly result in conflicts between opposed classes. Although adopting the same view on the subject, Maria Isabel Pereira de Queiroz and Roger Bastide differ on the orientation the individual agency must adopt in leading to social transformation. This article intends to show this difference, taking as reference the dialogue that both of them have kept with the French Sociology from whose intellectual tradition stems the discussion about actuation of individuals and groups in social change processes and the function that collective representations have on the conformance of yours performance.
\end{abstract}

Key words: Brazilian Social Thought; Sociology; Social Change; Subaltern Class Conscience

Doutora em Desenvolvimento, Agricultura e Sociedade pela Universidade Federal Rural do Rio de Janeiro. E-mail: doravasconcellos@ig.com.br. 


\section{INTRODUÇÃO}

As interpretações hoje tidas como clássicas afirmam que os tempos coloniais deixaram como legado uma herança determinante para o modo como se configurou a sociedade brasileira. Também tem sido bastante reconhecida a ideia de que o traço mais característico, e, sem dúvida, o mais problemático da nossa formação social, foi o fato de ter se consolidado aqui uma espécie de dominação despótica entre as camadas sociais que impediu a formação de classes sociais no país (FREYRE, 2001; VIANNA, 1987). Esse diagnóstico deu base para as interpretações que atestaram que no Brasil as camadas menos favorecidas não eram politicamente atuantes.

Entretanto, o pessimismo da intelectualidade brasileira do início do século XX diante da constatação da ausência de um povo brasileiro ativo foi compensado pela suposição de que a presença de uma cultura nacional polivalente, embora tenha dificultado que os conflitos sociais entre as camadas se tornassem conspícuos, impediu que o país seguisse orientações contrastantes, se esgarçasse em separatismos os mais variados. Salvava-se, assim, a nação diante do pessimismo característico dos ensaístas do século XIX, com a ideia de que somos um país desigual, mas coeso (SCHWARCZ,1993).

Essas duas constatações, a da ausência de um povo e a ideia de nação, estiveram presente no imaginário nacional, pelo menos até meados da década de 1940. Gilberto Freyre é talvez o autor mais expressivo do período devido ao entusiasmo que demonstrou ao perceber que a cultura patriarcal fazia as camadas sociais se relacionarem por meio de uma dinâmica acomodatícia (FREYRE, 2001) ${ }^{1}$. O que vale ressaltar é que, diante desse diagnóstico que também era um ideal de época, de que no Brasil as mudanças seguissem o ritmo lento, consolidou-se a certeza do imobilismo da camada subalterno, em particular da população rural. Daí a dificuldade do pensamento social, que se voltou para o mundo rural e suas heranças, em reconhecer a existência de um campesinato brasileiro (QUEIROZ, 2009).

Roger Bastide propôs uma mudança naquele paradigma ao elaborar uma nova interpretação do Brasil, mais afeita às demandas, atuações e representações das populações subalternas. A herança africana no Brasil sugeria um poder de contestação do negro à escravidão e ao regime patriarcal mais forte do que se imaginava. Com essa descoberta, Bastide descreveu uma dinâmica entre as camadas sociais marcada mais pelo conflito que pela acomodação. Assim, encontrara um novo padrão contestatório peculiar às camadas subalternas que não obedecia à dinâmica de conciliação de antagonismos, tal como previra Gilberto Freyre, mas aos princípios de cisões e participações. Ao que tudo indica, o princípio de cisão acentuaria as orientações divergentes entre as camadas sociais, o de participação, as contiguidades entre elas (QUEIROZ, 1978)².

Discípula de Roger Bastide, Maria Isaura também reconheceu o papel ativo desempenhado pelas camadas subalternas para a ocorrência de mudanças sociais no país. Ambos afirmam que a agência individual é o meio a partir do qual ocorre o aumento do dinamismo social em sociedades como a nossa, em que as desigualdades sociais entre as camadas dificilmente se materializam em conflitos de classes opostas. Ainda que apresentem esse ponto em comum, os autores divergem quanto à orientação que a ação individual deve assumir para que haja transformação social. Pode-se dizer que, por meio dessa discussão, Roger Bastide e Maria Isaura se voltam para o tema da consciência das classes subalternas no Brasil. Enquanto Roger Bastide se dedicou a estudar a consciência das classes

\footnotetext{
$1 \mathrm{O}$ autor chegou inclusive a defender que houvesse uma combinação entre os preceitos racionais e os pessoais para que não se pusesse em risco o que a sociedade patriarcal deixou de melhor: a lógica acomodatícia (FREYRE, 1982)

2 Segundo Maria Isaura, Roger Bastide considera que esse padrão contestatório, com o desenvolvimento histórico brasileiro, se disseminou por toda as camadas sociais, não sendo mais um comportamento típico do homem subalterno mas de toda a sociedade brasileira (QUEIROZ, 1978).
} 
subalternas por meio dos princípios das cisões e das participações imanentes ao candomblé, Maria Isaura a estudou observando os meios e os modos de vida dos grupos rústicos.

Neste artigo ressalta-se essa discussão tomando como referência o diálogo que os dois autores travaram com a sociologia francesa, da qual descenderia a discussão sobre a atuação de indivíduos e grupos e o papel desempenhado pelas representações coletivas na conformação de seus comportamentos. Ao que tudo indica, foi por meio das ponderações sobre a problemática da agência individual que eles elaboraram suas interpretações sobre a dinâmica social brasileira e os seus processos de transformação social.

\section{ROGER BASTIDE E A CONSCIÊNCIA DIRUPTIVA DAS CLASSES SUBALTERNAS}

No pensamento social brasileiro, a noção de sincretismo, que esteve fortemente presente de 1870 à 1930, primeiro sendo concebida em termos raciais (Nina Rodrigues) e depois em termos culturais, (Ś́lvio Romero), foi subsequentemente retomada por vários autores que fizeram sua revisão crítica, à exemplo do próprio Bastide e de Luís da Câmara Cascudo, que preferiram se valer dos termos "interpenetração de civilizações” (BASTIDE, 1979) e "xipofagia" (VASCONCELLOS, 2009), respectivamente, para analisá-la. A partir daí se lançou a hipótese de que no Brasil as diferentes orientações culturas compuseram uma dualidade, um triadismo ou uma correspondência paralelística que levou ao questionamento aqui os conflitos se equilibravam por meio de uma cultura nacional polivalente e apaziguadora que anulava as desavenças econômicas entre as camadas sociais. Notou-se que o apego a acervos culturais distintos traduzia um comportamento de luta que não podia ser desconsiderado. Daí a necessidade de se pôr em relevo a teorização de Bastide sobre a religião, pois nela se pode avaliar em que medida o tema do apego ao acervo religioso africano contém a questão das críticas que poderiam ser feitas ao regime patriarcal e escravocrata.

Retomar essa discussão permite explorar a ideia de que a singularidade da interpretação de Brasil de Bastide ganha destaque quando posta em relação ao legado teórico deixado pela sociologia francesa, da qual descenderia o autor. A despeito da divergência que existe entre seus integrantes, a escola francesa parece ter como perspectiva fundamental a ideia durkeimiana de que o social é fundado a partir das representações coletivas e de que é preciso haver uma conformação moral para que surja a vida em sociedade (ORTIZ, 1989). Embora posteriormente a sociologia francesa tenha complexificado o argumento durkheimiano da representação coletiva como algo coercitivo e homogeinizador, chegando até mesmo a identificar a presença de orientações conflitivas, os herdeiros dessa tradição intelectual pressupõem que as representações dissidentes são sempre permeáveis de algum modo à razão coletiva (QUEIROZ, $1983)^{3}$. Por seguir essa orientação, a sociologia francesa, de um modo geral, daria mais prioridade ao todo do que às partes, ou seja, mais à atuação das representações coletivas do que às individuais ou grupais. Vale lembrar que, para essa tradição intelectual, a sociedade é, sobretudo, uma instância moral, ou seja, erige-se a partir da coerção, da restrição e do amoldamento das inclinações individuais; é uma instância com força superior, exterior e anterior ao indivíduo que tem por finalidade despertar a coesão entre os homens.

Durkheim chegou a essa constatação observando as representações religiosas. Para ele, a crença religiosa seria a base do sistema classificatório humano e teria como fim último a congregação entre os homens. Por meio dela, as coisas seriam divididas entre dois termos separados e opostos: o sagrado e o profano. Por gerar uma visão bipartida do universo, o sistema religioso fundaria uma relação de coordenação e subordinação entre as coisas. O sagrado denotaria as coisas por assim 
dizer superiores, o ser divino e a sociedade; o profano, as coisas tangíveis e ordinárias que dizem respeito à esfera individual.

No seu estudo sobre as religiões primitivas, Durkheim descobre que a ideia de transcendência seria própria do próprio mundo social; a sociedade, por ser anterior, exterior, coercitiva ao indivíduo, despertaria a sensação de divino nos homens ou de algo que os ultrapassa. O princípio de sagrado nada mais seria do que a necessidade imperiosa da cooperação imposta pelo meio social (DURKHEIM, 1996, p.21).

O sagrado e o profano revelariam, então, a dupla existência e a dupla natureza do homem: a coletiva e a extraordinária; a individual e a ordinária. Por trás dessa visão bipartida haveria a ideia de que a consciência individual ou a vida profana, deixada a seu livre arbítrio ou integre às paixões, atuaria como uma força impeditiva à vida em sociedade. Durkheim considera, então, que a sociedade restringe o grau de liberdade individual ao permitir que esta se manifeste apenas na exata medida do livre curso do social. Sendo assim, para ele, a vida em sociedade não é um artifício ou arbítrio, pelo contrário, ela se explica pela própria sociedade e se elabora lentamente por meio da regulação da conduta do indivíduo contra sua tendência dispersiva. $\mathrm{O}$ intelectual defende, portanto, que as tendências irracionais do indivíduo sejam vencidas pela progressiva proeminência da consciência orgânica, da consciência social ${ }^{4}$.

$\mathrm{O}$ indivíduo, ao introjetar essas normas sociais ou a razão coletiva, tornar-se-ia insignificantemente reduzido em relação às suas forças. Durkheim menciona, então, uma força moral que atua tornando as representações individuas complementares umas às outras. Por conceber que o social se forma dessa maneira, ele invalida as teorias revolucionárias que con- cebem a moral social como uma legislação revogável (CASTRO E DIAS, 1970).

Em contrapartida à sociologia funcionalista de Durkheim, vamos encontrar na teoria de Bastide que o individual não é fonte da desordem, do irracional e da afetividade porque o indivíduo pode raciocinar simultaneamente por meio das diferenças e das contiguidades. Durante sua estada no Brasil, Bastide descobrira a existência de um homem que, apesar de assimilar os valores católicos portugueses, conseguia salvaguardar os valores religiosos africanos dissidentes num comportamento de luta contra a escravidão. Tudo leva a crer que com o princípio de cisão ele revelaria um mecanismo importante para que se forme representações divergentes, marcando sua diferença em relação à escola francesa. Ele contrariaria a perspectiva que enxerga a religião como uma emanação do social, como uma força que demonstra a proeminência do social sobre o individual ao considerar que o sagrado pode se configurar como uma força que transcende ao social, isto é, que o supera por emanar do indivíduo, obedecendo a estrutura do grupo ao qual ele faz parte.

É que o homem de raízes africanas, ao contrário, do euro-ibérico, não tinha o princípio da contradição como fundamento de seu pensamento. Afinal, ele raciocinava simultaneamente segundo a lógica das participações e das cisões. Daí decorria que a presença de orientações culturais contrastantes não impunham o peso de uma escolha para os africanos. O escravo, embora se encontrasse premido entre a filosofia ocidental capitalista e a filosofia comunitária animista fetichista, podia passar de uma à outra sem que isso representasse para ele um drama pessoal graças ao princípio de cisão e de participação. Ao que tudo indica, enquanto as participações acentuavam as coincidências, as cisões ressaltavam as divergências entre esses sistemas de pensamento. Entretan-

4 Assim como para Rousseau e para Hobbes, Durkheim concebe que há uma discrepância entre o indivíduo e a sociedade. O homem seria naturalmente refratário à vida em comum; a ela ele só se resignaria pela força. A obra do social consistiria na instituição e organização dessa coerção. Entretanto, para Durkheim, a sociedade não seria produto de um pacto social, como acreditavam Hobbes (HOBBES, 1979) e Rousseau (ROSSEAU, 1988); ela se originaria de um poder regulador que emana do ser coletivo, de uma moral coletiva (CASTRO e DIAS, 1976). 
to, filiando-se ao mundo animista fetichista dos candomblés, o escravo fazia do princípio de cisão o seu principal operador. Sendo assim, ainda que a população cativa adotasse os deuses católicos, ela o fazia como um recurso para salvaguardar o panteão africano. Embora os valores euro-ibéricos influenciassem as relações e a estrutura interna do homem subalterno, tais valores eram convertidos nos termos dos valores comunitários africanos, o que revelava um comportamento de luta contra o regime patriarcal escravocrata. Daí Bastide ter concluído que a esfera do sagrado, quando referida aos valores animista-fetichistas do homem subalterno, gerava um movimento de transcendência em relação ao social opressivo. Em termos mais teóricos e abstratos, o intelectual descrevia um processo de reinterpretação cultural que ocorria no plano da agência individual que permitia o homem subalterno converter os valores euro-ibéricos nos termos dos valores africanos. Denominou esse processo de interpenetração de civilizações.

Por meio dessa descoberta, salientou a importância do indivíduo como elemento modificador dos procedimentos e dos processos sociais. A razão coletiva não tinha uma força tão absorvente a ponto de anular a formação de orientações contrárias (QUEIROZ, 1983). E mais: observando o misticismo africano, Bastide descobre que, ainda que o transe fosse individual, ele obedecia ao conjunto estruturado de relações grupais peculiares aos terreiros. A mentalidade do homem subalterno variava conforme a posição do indivíduo e dos grupos em suas hierarquias internas. Deste modo, se afastava das concepções durkheimianas ao supor que a atuação de indivíduos subalternos nem sempre representava uma afronta à existência da vida coletiva, pois as representações individuais sempre faziam re- ferência à estrutura do grupo no qual estavam inseridos 5 . Bastide identificava, então, de um novo tipo de relação entre as partes e o todo, em que as partes gozavam de relativa autonomia. E fazia uma observação importante: tal prerrogativa provinha da atuação individual e era conquistada por meio do princípio de cisão. Tal princípio de corte permitia a compartimentalização da realidade de tal modo que dois mundos diferentes, senão opostos, coexistissem: o mundo comunitário dos candomblés e o mundo patriarcal capitalista.

Maria Isaura assinala que o princípio de cisão permitia a formação de representações dissidentes, mas de tal modo que as orientações contrastantes permanecessem justapostas, sem redundar em conflito. Ao afirmar isso, a autora aponta que Bastide foi o primeiro autor, de uma vasta literatura, a considerar que a heterogeneidade das orientações contribuía para a estabilização da sociedade brasileira (QUEIROZ, 1983). Se isso se confirmar, há que se averiguar a possibilidade de o autor ter permanecido preso aos axiomas da sociologia francesa, a despeito de ter querido fazer sua crítica. ${ }^{6}$

Renato Ortiz, por sua vez, por meio de uma referência a Gramsci, sugere que o princípio de cisão bastidiano afirmava a consciência da classe subalterna como algo fragmentado, composto de valores provenientes tanto da hegemonia, como da contra hegemonia. E assim, ele chama atenção para o fato de que esse tipo de consciência imprimia um dinamismo à sociedade, ainda que o efeito seu global fosse a estabilização. Afinal, se a heterogeneidade denotava a dificuldade de construção de um discurso contra-hegemônico por parte da camada subalterna, também demonstrava o inverso, que a hegemonia também é algo árduo de ser alcançado. É que justamente por ser heterogenia, a consciência da camada subalterna indi-

\footnotetext{
5 No caso brasileiro, a sua referência eram as comunidades axiológicas formadas pelo candomblé (BASTIDE, 1974)

6 É necessário averiguar se Bastide supõe existir uma modalidade de dialética que é complementar e não oposta, o que marcaria um reconciliação sua com a sociologia durkheimiana por meio de Georges Gurvitch. Vale a pena lembrar que Gurvitch, embora afirme se atentar tanto para o caráter sincrônico, como para o diacrônico dos fatos sociais, supõe subsistir inevitavelmente um elemento sincrônico, um equilíbrio ou uma coesão relativa entre as formas de sociabilidade, os determinismos de classe e determinismo da sociedade global, este tendo procedência sobre as demais instâncias por concorrer para estabilização. Por isso quando ele analisa a estrutura dos grupos ele afirma que o político ou o econômico são apenas alguns dentre os muitos setores da atividade humana (BASTIDE,1971). Há que se considerar se a lógica da analogia descrita por Bastide por meio do candomblé originava uma dialética de complementaridade, tal como supôs Gurvitch.
} 
caria que também os valores hegemônicos ou a ortodoxia encontram-se fragmentados. Daí a cultura popular possuir um caráter de resistência, ainda que não apresente um componente revolucionário pelo fato do espaço utópico, pela sua heterogeneidade, ainda se subordinar a ortodoxia (ORTIZ, 1980).

Neste artigo, sugere-se a possibilidade da cisão resultar numa atitude de ruptura ou negação dos valores socioeconômicos hegemônicos, a fazer com que as relações sociais entre as camadas sociais no Brasil sejam mais conflitivas. Cabe indagar se não era isso que Bastide afirmava ao sugerir que religião animista fetichista resultava num movimento de transcendência em relação ao social opressivo. Resta saber se com o princípio de cisão a camada subalterna adotava os valores euro-ibérico, mas para reinterpreta-los nos termos da lógica africana o que indicaria a possibilidade da camada subalterna possuir uma auto-representação independente da camada senhorial. É necessário averiguar se o princípio de cisão, ao invés de reforçar a razão coletiva patriarcal, escravocrata e capitalista, promovia os valores comunitários africanos. Há que se considerar a possibilidade do princípio de cisão originar uma consciência disruptiva, pelo menos no que se refere aos aspectos socioeconômicos (CARDOSO, 1987). Quem sabe o princípio de cisão, justamente por se basear no mecanismo de reinterpretação, indicava a possibilidade de conversão de uma prática socioeconômica capitalista em comunitária?

Se o princípio de corte realmente cumprir essa função, ele pode contribuir para o questionamento da ideia de que a família patriarcal foi o núcleo estabilizador e o eixo de sustentação para um estrato social amorfo composto de escravos e homens livres que estavam à margem da ordem social. Se tal princípio apresentar essa dimensão crítica, ele pode ser um marco teórico interessante que assinala a existência de uma multiplicidade produtiva e de outras formas de relações sociais no interior da sociedade brasileira que não seguiam a lógica acomodatícia preconizada por Gilberto Freyre. Mais que isso: pode suscitar o questionamento da interpretação que postulava a ideia de que a população que não obedecia aos ditames da casa-grande estava integre ao reino de natureza. Esta suposição de que não havia qualquer norma cultural a regê-la embasava a certeza de que o povo brasileiro estava impossibilitado de participar de qualquer vida coletiva, a não ser se adequando a ótica da casa-grande (CORRÊA, 1981). O princípio de corte pode se configurar como uma contundente crítica a essa tradição intelectual ao indicar a existência de uma lógica comunitária não subsumida à lógica capitalista. E mais: pode ter contribuído para que as gerações subsequentes pudessem reconhecer outras formas de organizações familiares e a população rural como ativa politicamente.

\section{MARIA ISAURA E A CONSCIÊNCIA PRO- PICIADA PELA BARGANHA POLÍTICA}

Pode-se dizer que a crítica de Roger Bastide à sociologia francesa foi reafirmada em novos termos quando ele entrou em contato com a sociologia brasileira. Ao que tudo indica, a partir do estudo do mundo dos candomblés, o intelectual anteviu a possibilidade de indivíduos e grupos subalternos produzirem representações dissidentes em relação às normas coletivas hegemônicas, revelando um comportamento de luta que tinha passado despercebido pela tradição ensaística que tinha Gilberto Freyre como seu principal representante. Assim como os sociólogos franceses, a ensaística conservadora de Freyre produzia uma visão harmônica da sociedade brasileira ao supor que os conflitos se equilibravam por meio de uma cultura nacional conciliadora, deixando pouco espaço para a atuação dos indivíduos e grupos subalternos.

A sociologia de Bastide encontrou eco no cenário intelectual brasileiro transformando-se numa vertente intelectual que teve em Florestan Fernandes, Antônio Cândido, Gilda de Melo e Souza e Maria Isaura Pereira de Queiroz seus principais representantes. Dentre todos esses autores, pode-se dizer que Maria Isaura foi talvez a intelectual que deu 
maior continuidade à discussão sobre o poder de reação dos indivíduos e grupos subalternos em relação a uma norma coletiva apaziguadora de conflitos sociais.

Tal discussão foi ressignificada por Maria Isaura nos seus estudos sobre o mandonismo local. Por meio deles, ela buscou identificar os fundamentos sociais da ação social num contexto como o brasileiro em que a dominação política se baseia num sistema de reciprocidades assimétricas. Ao empreender uma "sociologia dos fatos políticos", ela encarou o mandonismo local como um produto da vida em grupo e chegou a conclusão que a dominação política assentava-se sobre a estrutura da parentela, grupo que unia indivíduos hierarquicamente desiguais em torno do ideal de reciprocidade de favores que impunha alianças de sangue, espirituais (compadrio), matrimoniais, econômicas e políticas. A despeito de reconhecer o componente de dominação nas relações sociais do meio rural, ela concluiu que o voto integrava uma ampla e complexa relação de reciprocidades a partir da qual a barganha política tornava-se possível. É que a troca de favores impunha a necessidade da contraprestação a todos os indivíduos da escala social, não importa em qual posição estes estivessem. Sendo assim, mesmo os fazendeiros tinham obrigações a cumprir junto ao campesinato, caso não o fizessem o elo social era rompido. Daí a possibilidade da barganha política pela camada subalterna no campo.

Por meio do ideal da reciprocidade ou da pessoalidade nas relações sociais, Maria Isaura explicava o fato da contenda política, no Brasil, ser uma questão de honra, daí a chefia ser algo sempre disposto a ser quebrada. Essa instabilidade fazia com que as parentelas se formassem e se desfizessem meio que ao sabor do acaso. Isso explicava a possibilidade da barganha política mesmo em áreas altamente estratificadas, já que sempre havia a possibilidade do sitiante se filiar a outro chefe político, caso não fosse obtido o favor almejado. A autora supõe, então, que as regiões hierarquizadas de agricultura de exportação também era possível a barganha política (QUEIROZ, 1976b).

A escolha na hora do voto se tornava ainda mais factível em zonas de abastecimento, em que os grupos subalternos se inseriam na estrutura coronelística por meio de relações indiretas, mediadas por lideranças do tipo primus inter pares. Esse tipo de representatividade mitigava as relações de mando ao interpor entre o chefe local e o sitiante, uma liderança intermediária, constituída entre iguais (QUEIROZ, 1976). Maria Isaura supõe que a lógica do ideal de ajuda mútua propagada nos bairros rurais ${ }^{7}$, por formar esse tipo de liderança, conferia um dinamismo ainda maior às relações sociais e aumentava a possibilidade da barganha política no campo.

A socióloga caracteriza, então, a política nacional como um sistema cujas relações de mando são amenizadas. A rede de reciprocidades assimétricas já havia sido formulada por Oliveira Vianna em Populações Meridionais do Brasil (VIANNA, 1987), e adotada por Victor Nunes Leal para definir o coronelismo como sistema (LEAL, 1975). Ela confere, contudo, um novo significado às relações de dominação ao introduzir a dimensão da agência ou simplesmente da ação social em sua análise. A sua intenção foi evidenciar o caráter ativo do homem rural e o caráter dinâmico das relações políticas no Brasil ao pontuar a possibilidade da barganha política no campo, perspectiva que a investigação somente sistêmica pouco atenta à agencia individual não alcançava (BOTELHO, 2007).

Entretanto, Maria Isaura não deixa de reconhecer que apesar de o camponês ser uma figura ativa e combativa, ele tinha uma razão conciliadora, pois a barganha política, embora provocasse uma relativa sujeição do mandão local, ao impor a ele uma série de obrigações,

\footnotetext{
$7 \mathrm{O}$ bairro rural era formado por famílias conjugais autárquicas dispersas geograficamente que se reuniam periodicamente em função do ideal da ajuda mútua vicinal. Tal organização era composta normalmente de sitiantes independentes que se congregavam em trono do trabalho cooperativo ou do trabalho vicinal e das festas típicas da religião rústica. O bairro rural não era estratificado internamente (QUEIROZ, 1967).
} 
não levava ao questionamento da ordem social assimétrica e hierárquica. Pelo contrário, se configurava como um tipo de contestação que era compatível a ela. É que a barganha política, mesmo quando era fomentada no interior dos bairros rurais e originava uma liderança de primus inter pares, obedecia à lógica da reciprocidade de favores que acontecia no interior das parentelas. Vale lembrar que as parentelas, com sua organização vertical, se estendiam de alto a baixo da estrutura social e englobavam, por meio de relações indiretas, os bairros rurais. Há quem diga, por isso, que a parentela na obra de Maria Isaura se configura como um fato social total (CARVALHO, 2010) . $^{8}$

Deste modo, ela não deixava de afirmar que as relações de dominação pessoal no interior das parentelas seriam constitutivas, também, das relações de solidariedade social internas ao campesinato. Contudo, o fato da mudança se localizar no plano da agência individual e se manifestar no uso do voto como "posse" para uma barganha política é visto com otimismo por Maria Isaura. É que a barganha política possibilitaria aos atores agirem e responderem ativamente ao contexto das estruturas de dominação em que se inseriam. Por apontar os condicionantes e variáveis estruturais em que as transformações acontecem, há quem pontue a necessidade de se avaliar se, com esta concepção de mudança, a socióloga indicaria uma forma não-voluntarista de se aumentar o dinamismo do mundo agrário (BOTELHO, 2007).

É talvez por meio de um paralelo com a teoria da dádiva de Marcel Mauss, de onde a teoria da lógica da reciprocidade de favores se inspira, que o otimismo de Maria Isaura se torna mais claro. Neste artigo, faz-se menção à interpretação que supõe que Mauss, com sua teoria, afirmou existir uma complementaridade entre os valores não capitalistas contidos na dádiva e os valores capitalistas da sociedade envolvente (LANNA, 2000). Essa mesma ideia de complentaridade estaria presente na teoria de Maria Isaura.

Marcel Mauss supõe que a vida social nas sociedades arcaicas é ditada por um constante dar e receber9. É que a dádiva, ao impor a obrigação de se retribuir o favor alcançado, faria o "princípio da reciprocidade" ser o princípio de toda e qualquer aliança, sejam estas matrimoniais ou políticas. $\mathrm{O}$ intelectual chegava mesmo a considerar que a circulação de valores imposta pelo ideal da reciprocidade seria o momento do estabelecimento do contrato social ${ }^{10}$.

O importante a reter é que Mauss é ambíguo em relação à orientação econômica que a dádiva possui. Isso se evidencia na suposição de que a dádiva também está embutida na ideia de compra e venda das sociedades ocidentais modernas. Ele lembra que a dádiva, diferentemente da moeda, pressupõe certa inalienabilidade, mas essa inalienabilidade não se chocaria com a instituição do mercado. Muito pelo contrário, ela indicaria a possibilidade da convivência entre a dádiva e o mercado. Afinal para o autor, mesmo no capitalismo, no que se refere à instituição do trabalho, o trabalhador não se aliena de si $^{11}$. Para ele, seu trabalho possui uma alma, um valor que precisa ser retribuído e que é dado por uma razão de ordem pessoal inalienável. A dádiva, ao impor a necessidade da retribuição de um valor não alienável a todos os indivíduos, não importa em qual posição social estivessem, concorreria para a identificação de um interesse em comum entre as classes sociais, o que representaria uma oportunidade para que o sistema ca-

8 Não à toa Maria Isaura considera os bairros rurais como parentelas não-estratificadas. E-mail : e ao meu ver, poderia vir na introduo

9 Por isso, ele considera que a dádiva podia ser vista como uma espécie de fato social total que explicaria a lógica de todas as instituições primitivas, inclusive o modo como as trocas se davam.

10 Tanto para ele como para Durkheim, a economia seria regida por mecanismos espirituais. E assim mostraria Marcel Mauss que a morfologia social também é um fato simbólico.

11 Essa opinião seria contrária à desenvolvida por Marx, que supõe que no capitalismo, o trabalhador se aliena de si pela expropriação imposta pelas classes dominantes e pelo regime capitalista. 
pitalista fosse acoimado em seus vícios. Ou seja, a dádiva, com seus valores inalienáveis teria uma atuação complementar à lógica do mercado. O intelectual, com essa concepção da dádiva, proporia que os valores não capitalistas se adequassem à lógica capitalista ${ }^{12}$.

Do mesmo modo, Maria Isaura constata com otimismo que a lógica da ajuda mútua campesina era complementar à lógica capitalista da sociedade brasileira, que tinha como pilar a parentela e o seu ideal de reciprocidade de favores. De certo modo, essa compatibilidade indicava que a população campesina ainda tinha condições de se inserir na sociedade envolvente, sem o prejuízo de sua cultura e da prática da ajuda mútua. E o que é mais importante, esse tipo de incorporação abriria espaço para o tipo de atuação política que o homem rural conhecia: o da agência individual. Tudo indica que, como Mauss, Maria Isaura acredita na ideia de que a identificação de um interesse em comum podia acoimar os vícios da sociedade. Para ela, essa seria a condição para que houvesse a incorporação do campesinato na ordem social brasileira. Maria Isaura defende, então, a conjugação entre a lógica da ajuda-mútua campesina e a lógica capitalista da sociedade. Tal posicionamento foi defendido, ainda que a própria autora tenha reconhecido que tal padrão contestatório não levava ao questionamento da ordem social assimétrica brasileira, muito pelo contrário, representava uma acomodação a ela.

Sendo assim, Maria Isaura defendia a necessidade do perfilhamento da camada subalterna em relação à hegemonia da sociedade global, na qual as parentelas se configuram como um fato social total. Para ela, a instalação de uma dialética de complementaridade entre as camadas sociais permitiria que os atores subalternos se tornassem mais atuantes ao viabilizar o canal de contestação que lhe era mais propício: o da agência individual. Convém lembrar, entretanto, que a própria Maria Isaura reconhece que a dialética de complementa- ridade desempenhava uma função social conservadora (QUEIROZ, 1976c). Ou seja, a barganha mesmo que tornasse os indivíduos subalternos ativos politicamente, era compatível com a estrutura pessoal e hierárquica.

\section{CONSIDERAÇÕES FINAIS}

Há que se considerar a possibilidade de que Roger Bastide e Maria Isaura identifiquem dois diferentes tipos de tomadas de consciência possíveis para a camada subalterna no Brasil.

Em relação a Bastide, é necessário considerar a hipótese de que, com o princípio de cisão, ele estivesse anunciando a existência de um campesinato negro ainda na época da escravidão que se comportava como uma protoclasse (CARDOSO, 1987). Isto é, que se tornava mais atuante ao formar uma consciência fechada. Maria Isaura, ao contrário, ao supor que ao campesinato é necessário coadunar, mesmo que parcialmente, com a orientação capitalista da sociedade global que tem como pilar as parentelas, defenderia o contrário: a formação da consciência continente, que leva em consideração os interesses das demais classes sociais. Para ela, esta seria a condição para que o homem subalterno se torne mais ativo politicamente, ainda que sua ação tivesse uma função social conservadora.

Os termos "consciência fechada" e "consciência continente", embora se remetam à teoria de Lukács, ajudam a entender como Roger Bastide e Maria Isaura divergem quanto ao tipo de consciência que as classes subalternas devem formar para que as relações sociais entre as classes se tornem dinâmicas.

Vale lembrar que Lukács complexificou a teoria marxista ao sugerir que a luta de classes só se efetivaria à medida que o proletariado formasse uma consciência fechada, ou seja, que elegesse apenas suas circunstâncias de vida e seus interesses como referência. Para o autor, a consciência aberta ou conti- 
nente, ao contrário, ao levar em consideração também os interesses das outras classes, mesmo as mais progressistas, impediria a percepção da racionalidade capitalista e do real fundamento da ordem burguesa: a progressiva expropriação dos meios de produção. Segundo Lukács, o resultado desse segundo tipo de tomada de consciência seria a não instalação do processo revolucionário ou de uma atitude questionadora dos valores e práticas burguesas (LUCKÁCS, 1974).

Se for correta esta interpretação do princípio de cisão ${ }^{13}$, pode ter havido uma mudança de paradigma no pensamento social brasileiro quando a noção de sincretismo é reelaborada por meio da noção de interpenetração de civilizações bastidiano. Essa perspectiva pode marcar uma possível divergência do autor em relação ao ensaísmo brasileiro, que concebia os problemas na escala da nação, preconizando soluções para a mesma como se ela fosse um todo monolítico e deste modo, passava por cima dos antagonismos de classe (WEGNER, 2008, p.292 apud CANDIDO, 1990, p.4-5) Esta mudança de paradigma se torna mais concebível quando referida à sociologia francesa, que parece seguir a mesma orientação do pensamento social brasileiro.

Maria Isaura, por sua vez, parece adotar um raciocínio que lembra o de Durkheim, ao situar a mudança num dinamismo inverso: no livre curso do social, que, no caso brasileiro, se estrutura pelas parentelas. O seu otimismo ao verificar que a atuação dos indivíduos, no Brasil, respeita o limite dado pelas relações de solidariedade pessoal assimétricas se revelaria pela crença de que assim as mudanças se tornam exequíveis.

Recebido em: 13/11/2015

Aprovado em: 10/04/2016

\section{REFERÊNCIAS BIBLIOGRÁFICAS}

ANDERSON, Perry. Considerações sobre o marxismo ocidental. Nas trilhas do materialismo histórico. São Paulo: Boitempo Editorial, 2004.

BASTIDE, Roger. Brasil: terra de contrastes. São Paulo; Rio de Janeiro: DIFEL, 1979.

. Les religions africaines au Brésil. Vers une sociologie des interpénétrations de civilisations. Paris: Press Universitaires de France, 1960.

- As Américas negras: as religiões africanas no novo mundo. São Paulo: Editora da universidade de São Paulo, 1974.

. O candomblé da Bahia: rito nagô. São Paulo: Companhia das Letras, 2001.

- As contribuições culturais dos africanos na América Latina; tentativas de síntese. In: QUEIROZ, Maria Isaura Pereira (Org.). Roger Bastide: Sociologia São Paulo: Ática, 1983.

. Ensaio de uma estética afro-brasileira. In: Roger Bastide. FREHSE, Fraya e TITAN JR, Samuel (org). Impressões do Brasil. São Paulo: Imprensa Oficial, 2011.

- Introdução ao estudo do termo de "Estrutura". In: BASTIDE, Roger (Org.). Usos e sentidos do termo "Estrutura". Editora Herder: São Paulo, 1971.

BOTELHO, André. Sequências de uma sociologia política brasileira. Dados, Rio de Janeiro, v. 50, n.1, p. 49-82, 2007.

CANDIDO, Antônio. Os parceiros do Rio Bonito. Estudo sobre o caipira paulista e a transformação dos seus meios e modos de vida. São Paulo: Livraria Duas Cidades LTDA, 1987.

CARDOSO, Ciro Flamarion. Escravo Ou Camponês? O proto-campesinato negro nas américas. São Paulo: Brasiliense, 1987.

CARVALHO, Lucas Correia. Transição e tradição: mundo rústico e mudança social na sociologia de Maria Isaura Pereira de Queiroz.

\footnotetext{
13 Nota-se uma certa imprecisão no pensamento de Bastide quando ele se refere aos princípios de cisão e de participação. Daí ser relevante um estudo que se dedique a mostrar como essa distinção aparece em seu pensamento. A esse respeito, ver o livro As religiões africanas no Brasil (Bastide, 1960).
} 
2010. Dissertação (Mestrado em Sociologia) - Instituto de Filosofia e Ciências Sociais da Universidade Federal do Rio de Janeiro, Rio de Janeiro. 2010.

CASTRO, Ana Maria de; DIAS, Edmundo Fernandes. Introdução ao pensamento sociológico. Rio de Janeiro: Eldorado Tijuca, 1976.

CÔRREA, Mariza. Repensando a família patriarcal brasileira. Caderno de Pesquisa, São Paulo, n. 37, p. 5-6, Maio de 1981.

CUNHA, Euclides da. Os Sertões. Rio de Janeiro: Record, 2002.

DURKHEIM, Émile. As formas elementares da vida religiosa. O sistema totêmico na Austrália. São Paulo: Martins Fontes, 1996.

FREYRE, Gilberto. Casa Grande \& Senzala. Rio de Janeiro: Record, 2001

. Rurbanização: o que é? Recife: Masangana, 1982.

FRY, Peter. Gallus Africanus est, ou, como Roger Bastide se tornou africano no Brasil. In: VON SIMSOM, Olga R. de Moraes (Orgs.). Revisitando a terra de contrastes: a atualidade da obra de Roger Bastide. São Paulo: FFLCH/ CERU, 1986.

HOBBES, Thomas. Leviatã ou Matéria, forma $e$ poder de um estado eclesiástico e civil. São Paulo: Abril Cultural, 1979.

LANNA, Marcos. Nota sobre Marcel Mauss e o ensaio sobre a dádiva. Revista Sociologia Política, Curitiba, n. 14, p. 173-194, jun. 2000.

LEAL, Victor Nunes. Coronelismo, enxada e voto: o município e o regime representativo no Brasil. São Paulo: Alfa-Omega, 1975.

LUKÁCS, Georg. História e consciência de classe. Estudos da dialética marxista. Porto: Publicações escorpiões, 1974.

MOREIRA, Vânia Maria Lousada. Nacionalismos e reforma agrária nos anos 50. Revista Brasileira de História. v. 18, n. 35, p. 329360, 1998. Disponível em: <http://www. scielo.br/scielo.php?script $=$ sci_arttext\&pi$\mathrm{d}=$ S0102-01881998000100015>.

NEGRÃO, Lísias Nogueira. Roger Bastide: do Candomblé à Umbanda. In: VON SIMSON, Olga R. de Moraes (Org.). Revisitando a terra de contrastes; a atualidade da obra de Roger Bastide. São Paulo, FFCH/CERU, 1986.

ORTIZ, Renato. Durkheim: arquiteto e herói fundador. Revista Brasileira de Ciências Sociais, São Paulo v. 4, n.11, p.5-22, out. 1989.

. A consciência fragmentada. Rio de Janeiro: Paz e Terra, 1980.

PEIXOTO, Fernanda Arêas. Roger Bastide, intérprete do Brasil: africanismos, sincretismo e modernização. In: BENJAMIM, Abdala Jr e SALETE de Almeida, Clara (Orgs.). Moderno de nascença: figuras críticas do Brasil. Rio de Janeiro: Boitempo, 2006.

QUEIROZ, Maria Isaura Pereira de. Uma nova interpretação do Brasil: A contribuição de Roger Bastide à sociologia brasileira. Revista do Instituto de Estudos Brasileiros. São Paulo, n. 20, 1978.

- O campesinato brasileiro. Petrópolis:

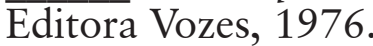

- O mandonismo local na vida política brasileira e outros ensaios. São Paulo: Alfa-Omega, 1976b.

. O messianismo no Brasil e no mundo. São Paulo: Alfa-Omega, 1976 c

.Uma categoria rural esquecida [1963]. In: WELCH, Clifford A.;MALAGODI, Edgard; CAVALCANTI, Josefa S. B.; WANDERLEY, Maria de Nazareth B.(Orgs.). Leituras $e$ interpretações clássicas. São Paulo: Editora UNESP, V.1, 2009.

. Images messianiques du Brésil. Guernavaca, México: SONDEOS (Una coleccion de studios sobre el fenômeno religioso en America Latina), n. ${ }^{\circ}$ 87, 1972.

- Bairros rurais paulistas. Separata da Revista do Museu Paulista. Nova série, v. XVII, São Paulo, 1967.

(Org.). A nostalgia do outro e do alhures: a obra sociológica de Roger Bastide. In: Roger Bastide: sociologia. São Paulo: Ática, 1983.

ROSSEAU, Jean-Jacques. Do contrato social. São Paulo: Nova Cultural, 1987.

SCHWARCZ, Lilia Moritz. O Espetáculo das Raças: cientistas, instituições e questão racial 
no Brasil 1870-1930. São Paulo: Companhia das Letras, 1993.

SIMSOM, Olga R. de Moraes (Orgs.) Revisitando a terra de contrastes: a atualidade da obra de Roger Bastide. São Paulo, FFLCH/CERU, 1986.

WEGNER, Robert. O sentimento de reforma agrária no pensamento social brasileiro. In: STARLING, Heloisa; RODRIGUES, Henrique Estrada e TELLES, Marcela (Orgs.). Utopias Agrárias. Belo Horizonte: Editora UFMG, 2007.

VASCONCELLOS, Gilberto Felisberto. A questão do folclore no Brasil. Do sincretismo à xipofagia. Natal, RN: EDUFRN: NCCEN, 2009.

VIANNA, Oliveira. Populações meridionais no Brasil. Belo Horizonte: Itatiaia; 1987. Niterói: Editora da Universidade Federal Fluminense: 1987. 